the apes themselves. By the same test, the attractive epithet of the 'missing link' had better be avoided until it is possible to answer with some clarity the question "With what?"

But one thing is clear. All the species of Australopithecus so far identified have come out of Africa, while the two African apes are the only plausible progenitors of the line. It is therefore excellent that the non-African members of the field expedition in Ethiopia have shouldered as a part of their obligation to their hosts to train a number of young people from Africa in the techniques of palaeoanthropology. Is it too much to hope that, in the long run, there will be freestanding expertise in this field not just in Ethiopia, but elsewhere in a continent from which too little good news comes? Mr Nelson Mandela might even take up the cause as a pan-African cause.

\section{Karl Popper is dead} Sir Karl Popper, who died a week ago, was a combatant
on every intellectual battlefield he could find.

SiR Karl Popper's influence on science notwithstanding, his most important book was The Open Society and its Enemies, published in 1946. It is not an anti-communist tract as often represented, but a definition of the principles of liberality by which a community of people may foster its own well-being, and that of its children. That is what he will be most remembered for.

But Popper, almost single-handed, brought about a decisive change in the status of theoretical propositions in science that will be permanent, and which has done much to moderate the tendency towards dogmatism that is the bane of some professional opinions. Popper himself has explained how his arguments on this score grew from his abreaction against the logical positivists who, at the turn of the century, commanded his native Vienna's philosophy. But Ernst Mach, both a positivist and temporarily Einstein's inspiration, and Popper were not so far apart.

Popper's influence in science derives from the simple observation that the propositions described in science as 'laws' cannot be verified, but can be proved false by a single counter-example. From that it follows that even apparently durable propositions are repeatedly falsified. Thus was Newtonian mechanics in turn succeeded by special and general relativity, for example. The effect is that prudent scientists no longer proclaim that they have found the "truth' about something, but merely that they have a better approximation to it. That is how it should be, in an open society.

True to his principles, Popper was catholic in his interests. As a philosopher, he dealt with everything. As a contributor to Nature, his more recent articles included a disputed proof that inductive probability is impossible $(302,687 ; 1983)$, a gedanken experiment to distinguish between the interpretations of quantum mechanics based on complementarity and that after which Einstein (and Popper) hankered and an advocacy of Wächterhäuser's theory of the origin of life on the surface of iron pyrites $(344,387 ; 1990)$.

\section{Genes and patent law}

Over-zealous patenting of mutated genes could decelerate discoveries the law intends to encourage.

If our genes are our birthright, are they patentable? That is the question raised afresh by last week's announcement that the first of the genes linked with inheritable breast cancer, known as $B R C A 1$, has now been identified and characterized (see pages $271 \& 279$ ). Under an agreement between the University of Utah (which gave us successively the first mechanical heart and cold fusion) and a company called Myriad, the identity of the gene will be the basis for a diagnostic test that will, then, be patented. Under present law, there is no reason why that should not be done. The question that arises is whether the law is sound.

On the face of things, patent law has worked excellently in this case. Although the link between the mutations of $B C R A 1$ so far identified and the occurrence of breast cancer in the families carrying it is far from clear, it is certain to be an invaluable tool in the search for other families in which early-onset breast cancer is apparently inherited. It should also serve as a means of genetic counselling for those at risk. In that sense, it is an illustration of the patent system at its best that entrepreneurs have ventured time and money on the search for a diagnostic test. Are these not exactly the circumstances in which they deserve patent protection for their efforts?

There are several grounds for doubting that simple proposition, not the least of which is that the hunt for these particular genes has occupied many other groups, mostly at academic institutions, for several years, many of whom have now been pipped at the winning-post. That spells wasted effort, to say the least of it. It probably also implies a new degree of deliberation in the way that academic research groups share information about their work with industrial enterprises. The time could come when research grant applications are routinely negotiated with potential industrial partners before being sent off to grant-making agencies. By creating new restraints, the result could be a deceleration of the pace of research in molecular genetics.

The consequences of that could be serious. Important though the new developments are in themselves, the big prize is that $B R C A 1$, its relative $B R C A 2$ and the other predisposing genes yet to be recognized and mapped onto the human genome will in due course provide clues to the mechanism of sporadic breast cancer arising in families that do not carry mutated versions of the genes so far identified. Much the same is likely to be true throughout the world's several human genome projects, where the effort spent on the identification of genes is likely to prove only a small fraction of that required to work out their normal function in the tissues in which they are expressed. Yet that is where clues to the treatment and prophylaxis of disease are most likely to arise. There will be hopeless muddles if these projects are undertaken only after the groups concerned have first made a deal with a potential patent-holder. 